\title{
An Empirical Investigation of the Antecedents and Outcomes of NPD Portfolio Success
}

\author{
Linda Kester, \\ Erik Jan Hultink, \\ Abbie Griffin
}

\begin{abstract}
Managing new product development (NPD) portfolios is difficult and little is known about how successful NPD portfolio management can improve overall firm performance. Despite regular calls in the literature for more research on NPD portfolio management, what successful NPD portfolio management means and how firms can achieve it remains unclear. For this reason, this paper combines theory and previous empirical findings to build a model of the antecedents and outcomes of NPD portfolio success. We generate and test 12 hypotheses with empirical data from 189 paired dyads in Dutch firms.

Our results show that all three dimensions of NPD portfolio decision-making effectiveness (i.e., portfolio mindset, focus, and agility) are associated with achieving the three dimensions of NPD portfolio success (i.e., strategic alignment, maximal NPD portfolio value, and portfolio balance), which in turn influences market performance. While a portfolio mindset and agility are related to all three dimensions of NPD portfolio success, focus is related only to strategic alignment and maximal value. No one dimension of NPD portfolio decision-making effectiveness or portfolio success is sufficient to achieve overall market performance. We also found several unexpected findings with important implications. For example, portfolio balance, one recommended measure of portfolio success, has no direct link to market performance, but operates through the other two dimensions of NPD portfolio success, i.e., strategic alignment and maximal portfolio value. We conclude our paper with implications for further theory development and testing on successful NPD portfolio decision-making, and with implications for managerial practice.
\end{abstract}

Address correspondence to: Linda Kester, Department of Product Innovation Management, Faculty of Industrial Design Engineering, Delft University of Technology, Landbergstraat 15, Delft 2628 CE, the Netherlands. E-mail: linda.kester@ sincer.nl. Tel: 015-2783068. 


\section{Introduction}

Over the past decades, firms have increasingly sought and implemented new product development (NPD) processes, first to help them develop individual new products efficiently and effectively, and later to manage their NPD activities from a holistic perspective for the overall portfolio of the firm. NPD portfolio management means that the firm engages in "a dynamic decision process whereby a business' list of active projects is constantly updated and revised. In this process, new projects are evaluated, selected and prioritized; existing projects may be accelerated, killed, or de-prioritized; and resources are allocated and reallocated to active projects" (Cooper, Edgett, and Kleinschmidt, 1999, p. 335).

Investing appropriately in product renewal and line extensions as well as in developing breakthrough innovations that may open up new marketplaces is important for most firms' long-term business growth and success (Chao and Kavadias, 2008; Hauser, Tellis, and Griffin, 2006). However, making these decisions is difficult as firms constantly need to decide, within the limits of the funds that they have to spend on NPD, in which products to invest, and how much at what point in time. They need to do so while simultaneously evaluating potential and ongoing NPD projects against the firm's overall strategic goals.

History has demonstrated how Texas Instruments, a technology-based firm, managed to survive by radically refocusing their NPD portfolio decision-making. For many years, the core competence of Texas Instruments was high-volume, low-cost manufacturing that resulted in an NPD portfolio of large volume products with little product variety (Prahalad and Hamel, 1990). When market demand shifted toward differentiated calculators with many features, this core competence became a weakness and the firm experienced significant market share erosion (Leonard-Barton, 1992; Rothaermel, Hitt, and Lloyd, 2006). However, Texas Instruments now has a broad and differentiated product portfolio and is a world leader in digital and analog technologies because they successfully refocused their NPD portfolio resource allocations to invest in new, differentiated products that grew new markets (Texas Instruments Annual Report, 2009, 2010, 2011).

\section{BIOGRAPHICAL SKETCHES}

Prof. Linda Kester is an assistant professor of strategic marketing at the Faculty of Industrial Design Engineering at the Delft University of Technology in Delft, the Netherlands. She received her Ph.D. from Delft University of Technology. Her research investigates antecedents and outcomes of strategic new product portfolio decision-making processes in large firms using both quantitative and qualitative research method- ologies. Her research on NPD portfolio management has received grants and awards from several international institutions, such as the PDMA, ISBM, MSI, and ISPIM. Linda derives passion and motivation from building bridges between the academic world and the business community.

Prof. Erik Jan Hultink is a professor of new product marketing and head of the Department of Product Innovation Management (PIM) at the Faculty of Industrial Design Engineering, Delft University of Technol- ogy, in Delft, the Netherlands. He is also a part-time professor of marketing at the Business School of the University of Portsmouth in the United Kingdom. He received his M.Sc. in economics from the Univer- sity of Amsterdam and his Ph.D. from Delft University of Technology, both in the Netherlands. His research investigates means for measuring and improving the processes of new product development and launch. He has published on these topics in such journals as International Journal of Research in Marketing, Journal of the Academy of Marketing Science, Industrial Marketing Management, $R \& D$ Management, IEEE Transactions on Engineering Management, and Design Management Review. This is his 27th paper in the Journal of Product Innovation Management.

Prof. Abbie Griffin holds the Royal L. Garff Presidential Chair in Mar- keting at the David Eccles School of Business at the University of Utah, where she teaches business-to-business marketing and first-year core marketing classes to M.B.A. students. Professor Griffin's reearch inves- tigates means for measuring and improving the process of new product development. She was the editor of the Journal of Product Innovation Management from 1998-2003. In 2009, Prof. Griffin was named as the fourth Crawford Fellow for her contributions to the field of innovation and new product development. Prof. Griffin is an avid quilter, skier, hiker, swimmer, and scuba diver. 
The above example illustrates the importance of NPD portfolio management for business success. However, managing NPD portfolios is difficult and little is known about how successful NPD portfolio decision-making can improve overall market performance. For example, Cooper et al. $(1999,2000,2001,2004)$ found that best practice firms evaluate their portfolios along three characteristics of success: strategic alignment, maximal value, and balance. Unfortunately, their research remained descriptive and did not reveal how NPD portfolio success may contribute to market performance. Several other studies (Bordley, 2003; Grewal, Chakravarty, Ding, and Liechty, 2008; Voss, Montoya-Weiss, and Voss, 2006) investigated optimal portfolio configurations and concluded that the relationship between portfolio diversification (i.e., one aspect of portfolio balance) and revenue may be best characterized by an inverted U-shape. In other words, the extremes of too little and too much diversification may negatively impact firm performance. On the other hand, Kester, Griffin, Hultink, and Lauche (2011) investigated how firms make portfolio decisions and identified three dimensions of portfolio decision-making effectiveness: making decisions from a portfolio mindset, while being focused, and allowing for agility. Their research did not investigate, however, whether and how effective decision making may impact NPD portfolio success and market performance.

Despite regular calls in the literature for more research (Cooper et al., 2001; Hauser et al., 2006), what success ful NPD portfolio management truly means and how firms can achieve it remains unclear. The present research addresses a part of this gap in the extant literature by empirically investigating the relationships between effective portfolio management and market performance. More specifically, we hypothesize and test whether NPD portfolio success is an outcome of a firm's effectiveness in NPD portfolio decision-making, and whether NPD portfolio success positively contributes to market performance. In doing so, we provide two major contributions to the extant literature. First, we develop and validate scales for NPD portfolio success as conceptually defined by Cooper et al. (1999, 2001), and for portfolio decision-making effectiveness as defined by Kester et al. (2011). Second, we develop 12 hypotheses and empirically test a model of NPD portfolio success that helps us understand how firms may improve market performance through effective NPD portfolio decision-making.

\section{Theoretical Development}

This section addresses NPD portfolio management from two perspectives. First, we review the extant literature on NPD portfolio success and develop hypotheses to relate NPD portfolio success to market performance. Next, we discuss three outcomes of NPD portfolio decision-making processes (Kester et al., 2011) and introduce hypotheses that relate NPD portfolio decision-making effectiveness to NPD portfolio success.

\section{NPD Portfolio Success}

The most significant empirical research investigating NPD portfolio management was conducted by Cooper et al. (1999, 2000, 2001, 2004). Recognizing that many firms were struggling with NPD portfolio management, they conducted an empirical survey, collecting single informant, self-reported data from 205 diverse businesses. Data were collected for six blocks of variables: portfolio management importance, portfolio management methods, management satisfaction with portfolio methods, portfolio management method performance, characteristics of the portfolio management approach employed, and general demographics. The main purpose of this descriptive research was to benchmark current practices for project selection and prioritization methods, and to develop an initial understanding of the results achieved from applying different NPD portfolio evaluation methods. Although their research revealed that managers overall were not satisfied with the methods used for making portfolio selection and prioritization decisions, their most important finding was the conceptual identification of three characteristics of successful NPD portfolios:

- Strategic alignment: The NPD portfolio composition reflects the firm's strategic business priorities;

- Maximal NPD portfolio value: The NPD portfolio has an optimal ratio between resource input and return; and

- Balance: The NPD portfolio is harmonious with respect to specific parameters, such as the different types of projects and their risk/reward characteristics.

Strategic alignment. Strategic alignment is the extent to which the NPD portfolio delivers against the strategic aspirations of the firm (Cooper et al., 2001). First, each project in the portfolio should individually support the firm's 
articulated strategy; the project should fit with specific market or technology areas as defined by the firm's business or innovation strategy. Second, a strategically aligned portfolio has projects incorporated in it that contribute to achieving the firm's strategic goals. For example, if a firm decides to enter a new market, then they must have projects in their portfolio that address that market opportunity. Finally, the breakdown in spending across all projects in a strategically aligned portfolio reflects the importance of each market or technology area in achieving the firm's strategic goals.

Cooper et al. $(2001,2004)$ used only two single items to measure strategic alignment in their survey. The self-rated best performing firms more often indicated that their projects were individually in line with the firm's strategy (best: $65.5 \%$, average: $57.2 \%$, and worst: $46.2 \%$ ), and that their overall resource allocations reflected their business strategy (best: $65.5 \%$, average: $30.7 \%$, and worst: $8.0 \%$ ). Although these findings suggest a positive relationship between strategic alignment and firm performance, statistically significant evidence of such a relationship was not provided nor was a multi-item scale for the "strategic alignment" construct developed or validated.

Several studies in related research domains indicate support for Cooper's argument that strategically aligned portfolios may lead to improved performance. For example, Chesbrough (2002) argues that firms should compose their internal corporate venturing portfolios to achieve either strategic or financial objectives, with the latter including investments that tap into future strategic opportunities. Lin and Lee (2011) also argue that the firm's future growth potential will be higher when the strategic linkages between a firm's core business and their corporate venturing investments are more related. These findings suggest that a strategically aligned NPD portfolio may contribute to achieving enhanced market performance. Hence, we hypothesize:

H1: A strategically aligned NPD portfolio is positively associated with a firm's overall market performance.

Maximal NPD portfolio value. Maximizing NPD portfolio value is defined as allocating resources to maximize the overall value of the portfolio in terms of a main company objective, such as profitability, return on investment, or likelihood of success (Cooper et al., 2001). In essence, maximal NPD portfolio value refers to the ratio between resource input (efficiency) and value output (effectiveness), in relationship to a firm's business objective. Hence, the optimal portfolio composition in terms of value differs by firm and depends on the strategic objectives and the markets in which the firm operates. For example, a leading firm in a highly innovative market may need to allocate a large proportion of its resources to high-impact, high-risk projects to achieve maximal NPD portfolio value. In contrast, a firm striving for cost leadership in a mature market may achieve maximal value if its NPD portfolio reflects lean investment decisions in incremental product improvements with a lower cost/ reward ratio.

Cooper et al. (2001) suggest that firms can achieve maximal NPD portfolio value by creating a list of rank-ordered projects, using one of several quantitative project scoring methods. From this list, firms then select and develop those projects with the highest value to the limit of the development budget.

Several empirical studies suggest that maximal NPD portfolio value may be positively associated with achieving market performance. For example, Cooper et al. (2004) found that best performing firms more often indicated that their portfolio contained high value projects (best: $37.9 \%$, average: $21.2 \%$, and worst: $0 \%$ ). In the theater industry, the inverted U-shape relationship between portfolio innovativeness and firm success had a maximum at about $25 \%$ radical innovations (Voss et al., 2006). These exploratory studies suggest that NPD port-folio value may positively contribute to achieving market performance. Hence, we hypothesize:

H2: Increased NPD portfolio value is positively associated with market performance.

NPD portfolio balance. Cooper et al. (2001) define a balanced NPD portfolio as one with an optimal spread in individual NPD project risk, and the right number of projects for the available resources. NPD portfolio risk/ reward most typically is evaluated on product newness and the technical and/or market risks versus expected financial rewards for the individual projects. Ideally, a firm should pursue incremental and radical innovations simultaneously (Jansen, Van Den Bosch, and Volberda, 2006). However, other portfolio balance indicators are spread across the different markets in which the firm operates (Cooper et al., 2001; Eggers, 2006; Lin and Lee, 2011); ratio between short- and long-term projects (Cooper et al., 2001); and project distribution across the various NPD stages (Cooper et al., 2001). The ideal "balance" may differ by firm, depending on firm strategy (Cooper et al., 2001), environmental complexity, and environmental turbulence (Chao and Kavadias, 2008).

It is easier to identify an unbalanced portfolio than to define what constitutes portfolio balance. Unbalanced NPD 
portfolios typically have more projects than their resources can support. As a consequence, managers are constantly occupied solving unanticipated problems, also referred to as "firefighting," which distracts them from focusing on those projects that are important in light of the firm's strategy (Repenning, 2001). The firm continues adding incremental projects to the portfolio to achieve short-term revenue goals at the expense of developing the larger-impact and higherrisk projects that help achieve the firm's long-term strategic goals (Barczak, Griffin, and Kahn, 2009; Cooper, 2008; Cooper et al., 2001). Overloaded portfolios may lead to strategic dilution and negatively impact a firm's business success (Cooper et al., 2001, 2004; Lin and Lee, 2011).

Recent advancements in the literature on portfolio diversification enhance our understanding of the impact of NPD portfolio balance on portfolio value and firm performance. For example, Bordley (2003) found that the overall value of the portfolio increased with diminishing returns as the number of new product entries launched by

a firm in the automotive industry increased. In the pharmaceutical industry, shareholder expectations of a firm's future cash flows related positively to having a wide portfolio targeting multiple therapeutic categories, and to portfolios targeting only a limited number of diseases (Grewal et al., 2008). In other words, shareholders valued an optimal (balanced) combination of portfolio breadth with depth because it allowed them to maximize the value of their portfolio.

Thus, while some studies suggest that NPD portfolio balance —or the lack thereof - may impact performance, other studies provide insights that suggest a more intricate role of portfolio balance. The latter studies suggest that firms with unbalanced portfolios will have greater difficulty aligning the portfolio to firm strategy and achieving a portfolio that delivers maximal value. Hence, we hypothesize that NPD portfolio balance has an indirect positive effect on market performance by functioning as a prerequisite for achieving a portfolio that is in line with the firm's strategy and that delivers maximal value. Hence, we hypothesize:

H3: NPD portfolio balance is positively associated with market performance through its positive impact on strategic alignment and maximal value.

\section{Portfolio Decision-Making Effectiveness}

Most studies investigating NPD portfolio management focus on optimal portfolio configurations but pay little attention to how firms decide to develop such a superior set of NPD projects. This is unfortunate as previous research has posited that the composition of the NPD portfolio ultimately results from how a firm makes NPD portfolio decisions (Hauser et al., 2006). Some studies have investigated aspects of portfolio decision-making (Kester, Hultink, and Lauche, 2009; McNally, Durmusoglu, Calantone, and Harmancioglu, 2009), but these studies have not uncovered the processes by which firms make NPD portfolio decisions. An exception is Kester et al. (2011), who inductively investigated portfolio decision-making processes through a multiple-case-study design. This study identified three dimensions of NPD portfolio decision-making effectiveness:

- Portfolio mindset: the firm has a complete overview of the entire portfolio, as well as in-depth knowledge about each individual NPD project;

- Focus: the firm focuses development efforts on those projects that achieve their long-term goals; and

- Agility: the firm is agile in how they make and implement NPD portfolio decisions.

Kester et al. (2011) further suggested that these three dimensions of NPD portfolio decision-making effectiveness are direct antecedents to Cooper et al.'s (2001) three characteristics of NPD portfolio success.

Portfolio mindset. An effective portfolio decision-making process provides an ongoing overview of all projects being considered, all those underway, where each project is in the NPD pipeline, and when each project is expected to launch into the market (Kester et al., 2011). Management in firms with a portfolio mindset makes decisions based on a complete understanding of all of the projects in the NPD portfolio and their interdependencies. The firm has an in-depth knowledge about each individual NPD project in the portfolio, and understands how each project relates to the overall portfolio and to achieving the firm's goals. 
Firms with a strong portfolio mindset select projects that are in line with the firm's strategy because these firms oversee how the portfolio as a whole matches their strategic aspirations (Kester et al., 2011). Firms who have a complete overview also may be better able to track the total number of NPD projects in the portfolio in relation to the available resources, and how these projects fit together as a whole to reduce overall portfolio risk. Finally, detailed project knowledge allows managers to differentiate between potentially high and low impact projects, while continuously comparing them with market developments. Hence, we hypothesize that a portfolio mindset positively contributes to achieving NPD portfolio success.

H4a: A portfolio mindset is positively associated with portfolio strategic alignment;

H4b: A portfolio mindset is positively associated with portfolio maximal value; and

H4c: A portfolio mindset is positively associated with portfolio balance.

Focus. Effective portfolio decision-making processes produce focused effort: Everyone in the firm, across all functional layers, knows what the development priorities in the portfolio are at all times (Kester et al., 2011). Firms with strong focus assign resources to those projects that are important to execute the long-term strategy. On the other hand, firms that lack a focused effort in NPD portfolio decision-making tend to chase innovation opportunistically; selecting incremental projects without paying attention to the composition of the overall portfolio and the achievement of longterm goals (Kester et al., 2011). These firms often end up in situations of "wanting to do it all" and not having enough resources available to initiate higher impact projects. Thus:

H5a: Focus is positively associated with portfolio strategic alignment;

H5b: Focus is positively associated with portfolio maximal value; and

H5c: Focus is positively associated with portfolio balance.

Agility. Effective portfolio decision-making means that the firm can quickly shift development resources across the portfolio when this is warranted, such as when new technologies are invented (Kester et al., 2011). Agile firms also can quickly eliminate projects from the portfolio that no longer fit the firm's strategy or that have become technology disadvantaged. Hence agility contains both a speed component (i.e., make and implement decisions fast) and a flexibility component (i.e., change the composition of the portfolio) (Kester et al., 2011).

Speed and flexibility have been investigated in several research streams. Research in the NPD domain predominantly has investigated product development speed as a means to achieve time-to-market advantages and increase new product profitability (Griffin, 2002; Langerak, Griffin, and Hultink, 2010). In addition, Eisenhardt and Martin (2000) found that new product performance depends on the speed and flexibility of the NPD process. Operations theory considers supply chain agility as a risk management initiative that enables firms to respond quickly to market changes and to adapt to disruptions in the supply chain (Braunscheidel and Suresh, 2009). Studies in this field indicate that agility is important to provide superior value to customers and to manage disruption risks (Braunscheidel and Suresh, 2009). Finally, the strategic decision-making literature argues that speedy decision-making impacts the outcome of the strategy process (Baum and Wally, 2003; Talaulicar, Grundei, and Van Werder, 2005). Strategically aligned NPD portfolios can be viewed as a desirable outcome of such strategy processes (Chao and Kavadias, 2008).

The combined findings from the NPD, operations theory, and strategic decision-making literatures indicate that portfolio decision-making process agility may be important to achieve strategically aligned NPD portfolios

(i.e., agility may help the firm quickly respond to changes in the market), deliver maximal value (i.e., agility may help to select high impact projects), and are balanced (i.e., agility may help to mitigate risks across the portfolio). Hence:

H6a: Agility is positively associated with portfolio strategic alignment;

H6b: Agility is positively associated with portfolio maximal value; and

H6c: Agility is positively associated with portfolio balance. 
Figure 1 presents the hypothesized relationships between portfolio decision-making effectiveness, NPD portfolio success, and market performance.

PORTFOLIO DECISION-

MAKING EFFECTIVENESS

NPD PORTFOLIOSUCCESS

MARKET PERFORMANCE

(Kester et al., 2011)

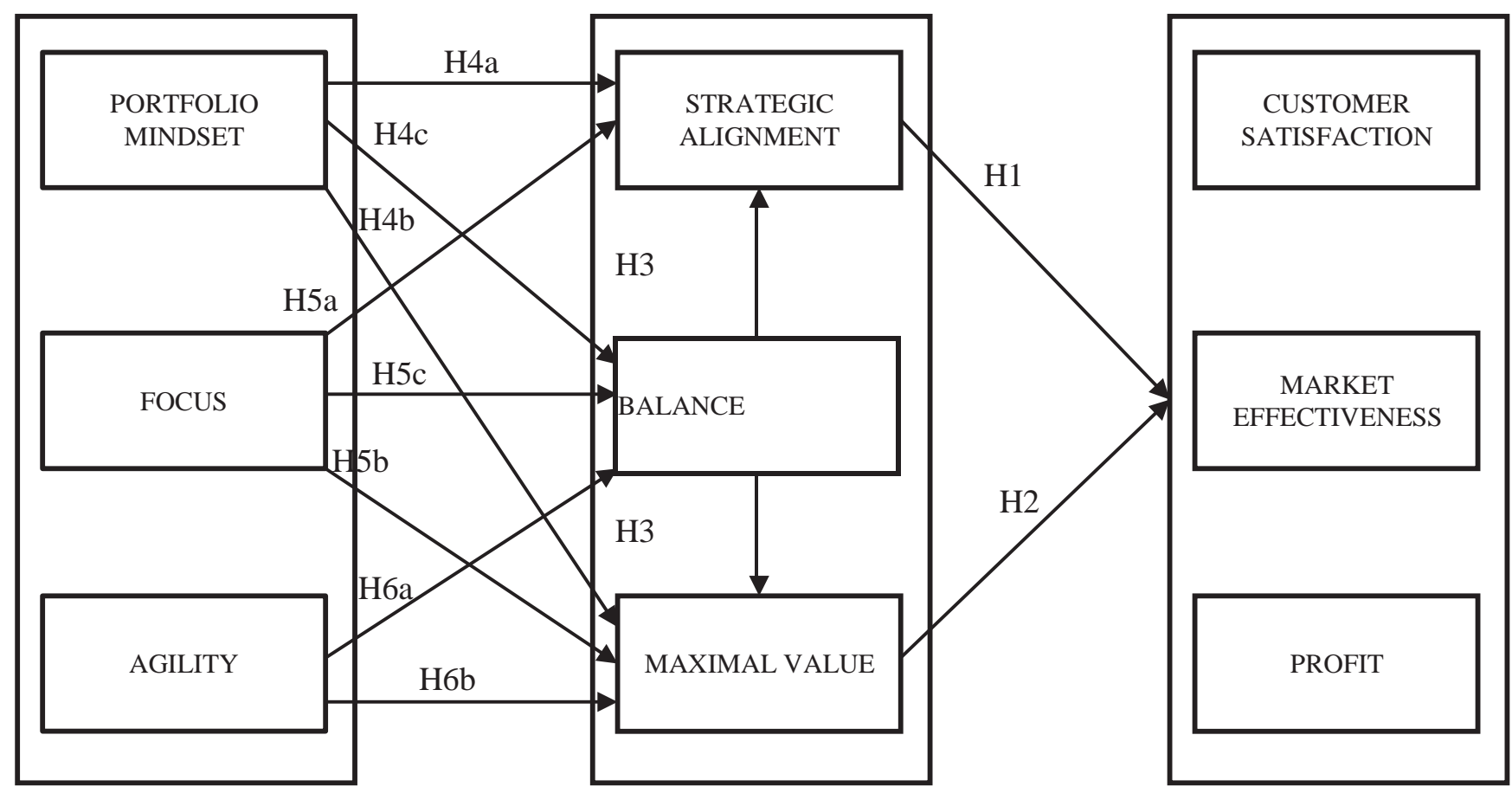

Figure 1. The Hypothesized NPD Portfolio Success Model 


\section{Methodology}

The research used a multiple-informant survey to empirically test our 12 hypotheses and the NPD portfolio success model. The following section first introduces the sample and data collection strategy. It then discusses the measure development procedure, and reliability and validity issues related to the final measurement instrument. We also address several additional procedures that we followed to validate and aggregate our multi-informant data sample.

\section{Sample and Data Collection}

Because NPD portfolio decisions are made at the strategic business unit level in the firm (Cooper et al., 2001), this was the unit of analysis for this study. Portfolio management is more complex when a strategic business unit has a reasonably sized portfolio with multiple projects in the pipeline. Therefore, only medium to large strategic business units were of interest.

The sample consisted of Dutch firms in multiple industries. The sampling strategy first identified a large set of companies using the REACH commercial database, which classifies 1.8 million companies in the Netherlands by size (employees), industry, and financial revenues. Only "medium" or "large" companies with more than 100 employees and an annual turnover exceeding 20 million euros were selected. The sample included a broad range of manufacturing industries (food, chemical products, electronics, industrial machinery, communications, and measuring equipment) and service industries (multimedia, telecom, and information technology [IT]), for which it was expected that firms regularly initiated innovation activities. Next, strategic business units appropriate to this research within the overall list were identified through visiting firms' web sites to determine their NPD activity levels. This procedure resulted in a potential sample of 338 firms.

Common method bias, the variance attributable to the measurement method rather than to the latent construct, can be a serious problem in the social sciences, as it can cause a discrepancy between observed and true relationships among constructs (Eid et al., 2008; Podsakoff, MacKenzie, and Podsakoff, 2003; Van Bruggen, Lilien, and Kacker, 2002). Using multiple informants with different perspectives on the phenomena of interest enhances convergent validity of the measurement instrument (Eid et al., 2008). To reduce potential common method bias problems, data were collected from two informants in each firm, each of whom had different responsibilities in making portfolio decisions:

1. Senior managers with NPD portfolio decision-making responsibility and authority; and

2. Middle managers with no portfolio decision-making authority, but who provided inputs to senior managers for making the portfolio decisions.

The research used a carefully designed data collection strategy to identify and personally approach the appropriate informants at each firm during a period of five months. Starting from the contacts in the REACH database, we used a snowball technique to identify appropriate informants in each firm. We had phone conversations with each potential informant to determine the person's knowledge about their firm's NPD portfolio management, and whether they either had portfolio decision authority or provided inputs to NPD portfolio decisions. We kept track of all conversations with the various people at the firms. Such a careful screening procedure is important to reduce systematic error in the response data (Van Bruggen et al., 2002).

When we identified one informant in a firm meeting the screening criteria, we used that contact to identify the second informant. We sent surveys to identified informants only after they personally confirmed that they were interested in participating. We promised each informant a report (in the form of a PowerPoint presentation) with the findings and an invitation to a seminar at which we would present the results. The seminar invitation motivated many informants to participate as it provided them with opportunity to network with managers from other companies interested in the topic. A total of 120 senior managers attended the seminar. 
After repeated personal contacts, 450 informants agreed to participate in the research. Of these, 399 informants $(87 \%)$ from 205 companies (76\%) completed the questionnaire. To compose the final dyadic sample, firms with only one informant were removed, leaving

378 informants from 189 firms (70\% of the original sample). Table 1 provides a summary of the firm sample characteristics.

Table 1. Firm Sample Characteristics

\begin{tabular}{|c|c|c|c|c|c|}
\hline \multirow[b]{2}{*}{ Industry } & \multicolumn{2}{|c|}{ Industry } & \multirow{2}{*}{$\begin{array}{l}\% \text { Sales from } \\
\text { New Products }\end{array}$} & \multirow{2}{*}{$\begin{array}{l}\% \text { Profit from } \\
\text { New Products }\end{array}$} & \multirow{2}{*}{$\begin{array}{l}\text { R\&D Spending } \\
\text { ( } \% \text { of Sales) }\end{array}$} \\
\hline & $N$ & $\%$ & & & \\
\hline Construction \& installation products & 80 & 21 & 42 & 41 & 5.6 \\
\hline Machinery \& electronics & 64 & 17 & 52 & 55 & 6.7 \\
\hline Consumer packaged goods & 44 & 11 & 38 & 39 & 6.8 \\
\hline Chemical products & 37 & 10 & 38 & 39 & 5.3 \\
\hline Durables & 30 & 8 & 60 & 64 & 7.4 \\
\hline Food ingredients \& agriculture & 27 & 8 & 34 & 38 & 7.3 \\
\hline Transport, storage, and communication products & 24 & 6 & 61 & 57 & 3.5 \\
\hline Services (financial, IT, and other) & 23 & 6 & 48 & 44 & 5.4 \\
\hline Pharmaceutical \& medical devices & 36 & 10 & 58 & 57 & 5.9 \\
\hline Utilities & 13 & 3 & 35 & 32 & 5.8 \\
\hline Average & & & 47 & 47 & 6 \\
\hline Total & 378 & 100 & & & \\
\hline
\end{tabular}

Key informants holding portfolio decision-making authority were senior managers working in marketing and sales $(35 \%)$, research and development $(\mathrm{R} \& \mathrm{D} ; 32 \%)$, or general management $(33 \%)$. Informants responsible for providing the inputs for portfolio decisions were either senior or middle-level managers, depending on the organizational structure of the firm. These managers predominantly worked in marketing and sales (42\%) or R\&D (42\%). Table 2 presents an overview of the informants' characteristics.

Table 2. Informant Characteristics

\begin{tabular}{lcrr}
\hline & Senior Managers & Middle Managers & Average \\
\hline Years of portfolio decision experience & $6.8(\sigma=5.3)$ & $6.1(\sigma=5.0)$ & $6.5(\sigma=5.2)$ \\
Years of NPD experience & $10.7(\sigma=8.4)$ & $9.6(\sigma=8.4)$ & $10.1(\sigma=6.6)$ \\
Years of work experience & $19.0(\sigma=8.3)$ & $18.1(\sigma=8.0)$ & $18.6(\sigma=8.2)$ \\
Years with firm & $11.3(\sigma=8.6)$ & $10.5(\sigma=8.4)$ & $10.9(\sigma=8.5)$ \\
Function: & & & $32 \%$ \\
Marketing \& sales & $35 \%$ & $42 \%$ & $39 \%$ \\
R\&D & $32 \%$ & $16 \%$ & $37 \%$ \\
General management & $33 \%$ & $25 \%$ \\
\hline
\end{tabular}

We assessed nonresponse bias by comparing early and late respondents. The $t$-tests between early (within seven days) and late (after three weeks) respondents showedno significant differences on any of the model's key variables. To assess informant bias, tests of significant differences were conducted between the answers provided by the portfolio decision authority managers and those providing inputs to portfolio decisions. Except for agility- speed $(p<.05)$, there were no significant differences. We also investigated informant biases in relation to the following firm and informant characteristics through ANOVA tests: functional area of informants $(\mathrm{R} \& \mathrm{D}$, marketing, and general management) $(p>.05$, except for customer satisfaction); years of portfolio decision experience $(p>.05)$; and primary target market (consumer, business-to-business, and government) $(p>.05$ except for agility speed). There were also no potential informant biases related to the industries in which the firms operated $(p>.05)$. 


\section{Measure Development}

Multi-item reflective scales were used to measure the constructs in the model. Existing scales were adapted to measure market performance. New scales were generated for the characteristics of NPD portfolio success as defined by Cooper et al. $(1999,2001,2004)$ and for the dimensions of NPD portfolio decision-making effectiveness as defined by Kester et al. (2011).

A carefully designed procedure was used to identify items and to develop a reliable and valid measurement instrument. Following Narver and Slater (1990), the items of all constructs were first pretested with eight academics holding senior faculty positions in marketing, innovation management, and organization theory, and with 10 senior managers from the medical device, consumer goods, chemical, and durables industries to assess face and content validity. Special attention was given to the newly developed scales. Most feedback pertained to ambiguities or difficulties in responding to the items. We used this feedback to revise the survey instrument, and to ensure clarity and appropriateness of the items. As part of our screening process, we screened for English language fluency. Thus, the survey was fielded in English.

Uni-dimensionality, the existence of a single construct underlying a set of items, is the most critical and basic assumption of measurement theory (Gerbing and Anderson, 1988). Therefore, we first conducted a pilot study with 67 managers to assess the underlying structure for the items of each scale. The respondents were members of the Product Development and Management Association's (PDMA) membership database in the Netherlands, and M.B.A. students with at least six years of work experience. The results from this pilot study showed that all scales were unidimensional and that the survey was therefore ready for final administration.

Exploratory factor analysis (EFA) based on principal components analysis extracted only one factor for each of the constructs with an eigenvalue of 1.0 as the cut-off point in the main study. All scales showed acceptable reliability $(\alpha>$ .70 ; Nunally, 1978) and the factor loadings were larger than .60, which exceeds the minimum value of .50 (Hair, Black, Babin, Anderson, and Tatham, 2005).

Scales from Vorhies and Morgan (2005) measured market performance in terms of customer satisfaction $(\alpha=.82)$, the extent to which the firm satisfied their customers compared with their major competitors; market effectiveness $(\alpha=$ $.82)$; the extent to which the firm achieved market share growth and increased sales compared with their major competitors; and profit $(\alpha=.90)$; the extent to which the firm achieved anticipated profitability compared with their major competitors. Each construct contained four items (Vorhies and Morgan, 2005).

As no scales existed, we relied on the definitions provided by Cooper et al. $(2001,2004)$ to define appropriate items for each dimension of NPD portfolio success. Strategic alignment $(\alpha=.88)$ was measured with five items reflecting the extent to which the firm's NPD portfolio was in line with the business goals and innovation strategy and the extent to which the firm's resource allocations reflected the firm's strategic priorities. To measure NPD portfolio balance $(\alpha=$ .82 ), we used five items assessing the number of projects the firm hadin development compared with available resources, the spread of NPD projects across the stages of development, the balance between incremental versus radical NPD projects, the extent to which the firm had mitigated portfolio risk across projects that were in different stages of development, and the extent to which the NPD projects in the portfolio were intended to serve growing versus mature markets. The scale for maximal NPD portfolio value emphasized monetary value rather than strategic or brand value, as suggested by Cooper et al. (2001). Maximal portfolio value $(\alpha=.78)$ reflected the extent to which a firm's portfolio composition helped it achieve their long-term growth and profitability goals. It was measured with four items assessing the extent to which the firm had high-impact projects in the NPD portfolio, had maximized the return from its portfolio in the past, and expected to maximize future profitability and market sales growth with the current NPD portfolio composition. The three dimensions of portfolio decision-making effectiveness represent new constructs. To operationalize these constructs, this study relied on the case study data provided by Kester et al. (2011). Portfolio mindset $(\alpha=.79$ ) used five items reflecting the degree to which the firm had a complete overview of their NPD portfolio, in-depth knowledge about each individual project, and how the individual projects related to the overall portfolio. Focus $(\alpha=.80)$ was measured with five items assessing the extent to which the firm's (long-term) objectives were reflected in their NPD portfolio priorities. Five new items examined a firm's agility $(\alpha=.74)$ in NPD portfolio decision-making. These items related to a firm's ability to be fast and flexible in making and implementing NPD portfolio decisions. 


\section{Reliability and Validity of Measures}

Confirmatory factor analysis (CFA) with LISREL 8.72 was used to analyze scale reliability and validity. The Appendix provides an overview of the scales and their properties. We estimated a measurement model to assess the convergent validity of the measures. The model showed an acceptable fit $\left(\chi^{2}\right.$ [d.f.] $=1182$ [601]), root mean square error of approximation $(\mathrm{RMSEA})=.05(90 \%$ confidence interval $=.05-.06)$, non-normed fit index $(\mathrm{NNFI}=.97)$, and comparative fit index $(\mathrm{CFI}=.97)$. The standardized factor loadings for each of the items on their respective latent construct exceeded the recommended cut-off value of .50 (Hair et al., 2005), with the exception of agility. Two items of the agility construct were just below the recommended cut-off value of .50 (.46 and .49 , respectively). Further investigation with EFA showed that the agility construct consisted of two components: flexibility and speed. A CFA with the two agility components did not significantly improve the model's fit indices. Thus, we decided to treat agility as a second-order construct.

The composite reliabilities in the Appendix and the $\alpha$ 's reported in Table 3 indicate that each construct exceeded the reliability threshold of .70 for Cronbach's $\alpha$ (Nunally, 1978) and .70 for composite reliability (Fornell and Larcker, 1981). The average variance extracted (AVE) estimates for each construct were larger than .50, which indicates that the variance captured by the latent construct is greater than the measurement error variance (Fornell and Larcker, 1981). To assess discriminant validity, we compared the squared correlation between each of the two scales with the AVE for each of the scales. The AVE was systematically higher than the squared correlations, suggesting discriminant validity (Fornell and Larcker, 1981). Because the correlation between portfolio mindset and focus was relatively high (.67), we additionally tested whether an unconstrained CFA model had a significantly lower $\chi^{2}$ value than a model in which the correlation between portfolio mindset and focus was constrained to 1 (Anderson and Gerbing, 1988). A $\chi^{2}$ difference test between the unconstrained and the constrained model $\left(\Delta \chi^{2}[\right.$ d.f.] $=114.09$ [1] $)$ confirmed discriminant validity. Thus, taken together, these tests satisfy the conditions for convergent and discriminant validity.

Table 3. (Based on Aggregated Data Sample Used for Model Analysis): Correlation Matrix and Cronbach's Alpha $(* * p<.01 ; * p<.05)$

\begin{tabular}{|c|c|c|c|c|c|c|c|c|c|}
\hline & 1 & 2 & 3 & 4 & 5 & 6 & 7 & 8 & 9 \\
\hline Customer satisfaction & .82 & & & & & & & & \\
\hline Market effectiveness & $56^{* \bullet}$ & .82 & & & & & & & \\
\hline Profit & $.29 * *$ & $.56^{*+*}$ & 90 & & & & & & \\
\hline Strategic alignment & $.37^{* \bullet}$ & $.25^{*+*}$ & .14 & .88 & & & & & \\
\hline Balance & $.29^{* *}$ & $.17^{*}$ & .14 & $.56^{+*}$ & .82 & & & & \\
\hline Maximal value & $.40^{* *}$ & $.33^{*+}$ & $23^{++}$ & $.56^{* *}$ & $.53^{+*}$ & .78 & & & \\
\hline Portfolio mindset & $.16^{*}$ & .07 & .01 & $.55^{*+*}$ & $.43^{+*}$ & $-41^{* *}$ & .80 & & \\
\hline Focus & $.16^{*}$ & .09 & .09 & $.56^{+*}$ & $.49^{+*}$ & $.40^{*+}$ & $.67^{*+*}$ & 80 & \\
\hline Agility & $.42^{* *}$ & $.29 * *$ & .13 & $.33^{*+*}$ & $.32^{++t}$ & $.36 * *$ & $.22^{* *}$ & $23^{*+*}$ & .74 \\
\hline Mean & 5.40 & 5.14 & 4.94 & 5.26 & 4.31 & 4.73 & 5.11 & 4.49 & 4.75 \\
\hline S.D. & .89 & 1.00 & 1.13 & .79 & .82 & .81 & .83 & .83 & .73 \\
\hline
\end{tabular}

\section{Dealing with Multi-Informant Data}

On the one hand, multi-informant data can be used to investigate potential effects of common method bias using additional statistical analyses (Podsakoff et al., 2003). Multi-informant data also may be used to create an aggregated data sample, in which the potential effects of common method bias are reduced (Van Bruggen et al., 2002). We used both approaches.

First, we compared two sets of measurement models: one in which the parameters for both groups (manager 1 and 2) were freely estimated; and one in which the parameters were set equal for both groups. $\chi^{2}$ difference tests between the constrained and unconstrained models were nonsignificant for the sets of variables (except for portfolio decision-making effectiveness, $p=.03$ ), which suggests that there are no significant differences infactor loadings, variances, and covariances. The observed means between the two groups are comparable. Further examination of the differences between the constrained and unconstrained models for portfolio decision-making effectiveness showed that the significant difference in $\chi^{2}$ is caused by a mean difference for agility-speed. These results concur with $t$-test analysis presented earlier and indicate that managers who have portfolio decision-making authority scored their firm higher on 
portfolio decision agility-speed than managers who provide inputs to portfolio decisions. Additional investigations using the CFA marker variable technique (Lindell and Whitney, 2001; Williams, Hartman, and Cavazotte, 2010) confirm that common method bias may not be a major problem in the data. ${ }^{1}$

However, because it is technically impossible to control for all potential sources of common method bias (Podsakoff et al., 2003), scholars recommend using responses from different informants for the dependent and independent variables (Podsakoff et al., 2003; Van Bruggen et al., 2002). Therefore, this research followed the multi-informant strategy recommended by Van Bruggen et al. (2002) to create the final aggregated data set.

We used the response data from the senior managers to assess market performance. Then, to construct the aggregated sample for the portfolio variables (portfolio decision-making effectiveness and portfolio success), we followed Van Bruggen et al. (2002), creating weighted means: "If the response accuracy of group members cannot be determined with certainty, then a weighted average of the responses from members that assigns higher weights to those more likely to be accurate should be used" (p. 471). The responses of the senior and middle level managers were weighted based on their experience with portfolio decision-making (Table 2).

\section{Results}

We used structural equation modeling (SEM; LISREL 8.72) to analyze our data and test the hypothesized relationships in the NPD portfolio success model. First, we investigated the hypothesized direct effects of NPD portfolio success on market performance, of balance on strategic alignment and maximal value, and of portfolio decision-making effectiveness on NPD portfolio success. This model had a poor fit to the data: $\left(\chi^{2}\right.$ [d.f.] $=97.05$ [15], $p<.001$, RMSEA $=.17$, NNFI $=.75$, and CFI $=.90)$. Investigation of the $t$-values showed that the path from focus to maximal value was not significant $(t=.84)$, suggesting that hypothesis $5 \mathrm{c}$ may not be supported. The paths from strategic alignment to market effectiveness $(t=1.11)$ and to profit $(t=.19)$ were also not significant, which suggests that strategic alignment may only have a significant effect on market performance through customer satisfaction.

We built another SEM model in which the path from focus to maximal NPD portfolio value, and the paths from strategic alignment to market effectiveness and profit were omitted. This model had a good fit to the data $\left(\chi^{2}\right.$ [d.f.] $=$ $26.35[15], p=.035, \mathrm{RMSEA}=.06, \mathrm{NNFI}=.97$, and CFI $=.99)$. All our direct effect hypotheses were supported $(\mathrm{H} 4$, H5, H6), with the exception of hypothesis 5c. Hypothesis 1, which suggested a positive effect of strategic alignment on market performance, was partially supported, whereas Hypothesis 2 was fully supported.

Next, we investigated the hypothesized indirecteffect of balance on each of the three dimensions of market performance (i.e., customer satisfaction, market effectiveness, and profit) using the bootstrapping methodology as proposed by Preacher and Hayes (2008). The results indicated that, taken as a set, strategic alignment and maximal value mediated the effect from balance to customer satisfaction. The total and direct effects of balance on customer satisfaction were $.31, p<.001$, and $.03, p=.69$, respectively. The total indirect effect through the two mediators was significant with a point estimate of .28 and a $95 \%$ bias-corrected confidence interval $(\mathrm{BCaCI})$ of .13 to .47 . Examination of the specific indirect effects showed that only maximal value was a mediator, with a point estimate of .16 and $\mathrm{BCaCI}$ of .13 to .47. Strategic alignment, with a point estimate of .12 and BCaCI of -.02 to .30 , did not significantly add to the model, as zero was included in the confidence interval. The bootstrap results also indicated that maximal value mediated the effect from balance to market effectiveness. The total and indirect effects were $.21, p<.05$, and $-.02, p=.88$, respectively. The total indirect effect through maximal value was significant with a point estimate of .22 and BCaCI of .12 to .37 . Finally, the total effect from balance to profit through maximal value was not significant (Beta $=.19$ and $p=.06)$. Hence, hypothesis 3 was partially supported. Figure 2 presents the final NPD portfolio success model.

\footnotetext{
${ }^{1} \chi^{2}$ difference tests between four nested models showed that the Method-R model, in which the variables are constrained to the baseline values, did not have a better fit than a model in which the method factor loadings are either constrained to be equal (Method-C model) or are estimated freely (Method-U model) (Williams et al., 2010).
} 


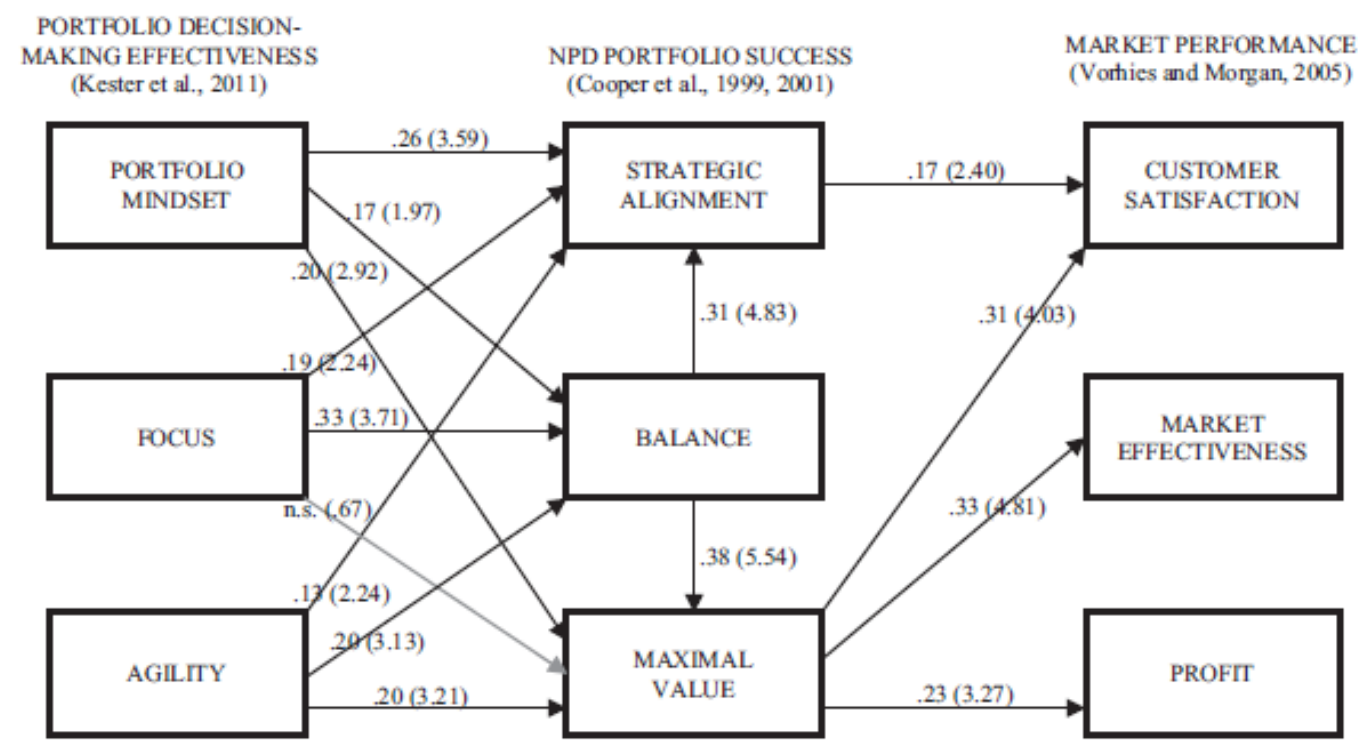

Figure 2. The Tested NPD Portfolio Success Model (Standardized B). Model fit: $\chi^{2}[$ d.f. $]=24.10$ [15]; $p=.06 ;$ RMSEA = .06; NNFI $=.97$; CFI $=.99$; n.s., not significant

\section{Discussion}

Previous research has posited that NPD portfolio success leads to enhanced market performance (Chao and Kavadias, 2008; Cooper et al., 1999, 2001). This present study provides empirical support for this assumption, but also finds that the relationship between NPD portfolio success and market performance is more nuanced than previously assumed.

One major new finding was that achieving NPD portfolio balance may be a prerequisite for developing a portfolio that is in line with the firm's strategy and delivers maximal value. This finding is important as itimplies that firms need to improve their NPD portfolio balance before they may be able to improve market performance through NPD portfolio success. Thus, firms need to critically analyze the extent to which their NPD portfolio has the right number of projects for the available resources, is balanced in terms of radical and incremental projects, and has a balanced set of projects spread across the markets that they intend to serve. Further, it is also important that a firm's NPD portfolio includes projects that are in various stages of development, and is balanced to mitigate risks across the projects. If a firm's NPD portfolio is not appropriately balanced, it may be difficult to achieve strategic and financial portfolio objectives.

Our findings also show that the three characteristics of NPD portfolio success each play different roles in helping firms achieve better market performance. Therefore, firms may want to emphasize different aspects of their NPD portfolio depending on the outcomes they want to achieve. For example, firms that want to improve overall customer satisfaction may want to critically evaluate the extent to which their NPD portfolio is in line with the firm's strategy. A disconnect between the firm's strategy ("what they say they do") and their NPD portfolio ("what they actually do") can lead to conveying incoherent messages to customers and thus lower overall customer satisfaction. On the other hand, firms wanting to improve performance in terms of profit or market effectiveness may want to focus on enhancing the overall value of their NPD portfolio by implementing high-impact projects that provide a source of revenue in the short and long run and provide platform or spin-off opportunities.

Our findings on how NPD portfolio decision-making effectiveness relates to NPD portfolio success have several important implications for future research and managerial practice. First, our findings indicate that decision-making focus (i.e., being able to set clear development priorities) is essential to prevent portfolio overload and develop a balanced NPD portfolio. However, setting clear development priorities alone is not sufficient to prevent portfolio overload and assure a well-balanced spread of projects in the portfolio.

Our results also suggest that firms that are fast and flexible in making and implementing portfolio decisions may be more capable of quickly eliminating those projects that are no longer interesting in light of a changing environment. Hence, 
agility can help free up resources in the portfolio, which contributes to achieving NPD portfolio balance. Firms that also make portfolio decisions from a portfolio mindset have both an overview and in-depth knowledge of the individual projects, which helps them understand how to mitigate risks across the entire NPD portfolio. Our findings thus suggest that even though focus represents an important antecedent to achieving portfolio balance, firms that are strong on all three dimensions of portfolio decision-making effectiveness are most likely to develop balanced NPD portfolios. Further, firms that make decisions from a portfolio mindset combine detailed project knowledge with an overall portfolio perspective that enables them to align the entire portfolio to their strategic goals. Not only do they understand how projects complement each other in achieving the strategic objectives, but they also understand where the strategic gaps are in their portfolio. Firms that also are strong in making focused portfolio decisions are capable of assigning resources to those projects that fill the gaps and contribute to achieving long-term strategic goals. Finally, agility helps firms quickly respond to strategic opportunities in the market and incorporate projects in the portfolio that reflect those opportunities. Thus, all three dimensions of portfolio decision-making effectiveness need to be considered to achieve a strategically aligned NPD portfolio.

Finally, the combination of a portfolio mindset and agility helps firms to develop NPD portfolios that deliver maximal value. While agility helps quickly anticipate market changes and incorporate projects reflecting emerging opportunities, a portfolio mindset helps firms understand how the portfolio should be configured to achieve maximal value for the firm. Having a continuous overview also means that the firm is able to detectpotential high-value projects in the portfolio that otherwise might be overlooked.

To conclude, this research empirically demonstrates the importance of effective portfolio decision-making processes for achieving NPD portfolio success and thus superior market performance. As such, our study both enhances the theoretical understanding of NPD portfolio management and helps improve managerial practice. The NPD portfolio success model shows managers how they can improve their market performance through NPD portfolio management and which actions may be taken to achieve more successful NPD portfolios.

However, the results also open up several opportunities for future research. While previous portfolio management research has predominantly focused on specialized industries, such as pharmaceuticals, automotive, and theater, our findings are based on a more general population of firms specifically focused on NPD. Therefore, it could be interesting to investigate whether some aspects of portfolio decision-making effectiveness and NPD portfolio success may be more or less important in specific industries. Future research also may want to investigate whether our findings hold for other types of portfolios, such as new venture or alliance portfolios. More research is needed to confirm these findings in different settings while extending the model by identifying antecedents to effective NPD portfolio decision-making and potential contingency variables.

\section{Limitations}

This study has several limitations that should be taken into account when interpreting the findings. First, the study used data from a sample of Dutch firms, which may limit the generalizability of our findings. Second, although objective market performance measures are desirable, we were not able to collect that information. However, to reduce potential error due to subjectivity, we followed Van Bruggen et al. (2002) and selected the most knowledgeable informant (senior managers with portfolio decision-making authority) to assess market performance. We also separated response data for the dependent variables (Podsakoff et al., 2003) and aggregated response data for the independent variables (Van Bruggen et al., 2002). Thus, although the study relied on subjective measures, it followed several strategies to reduce potential error. Third, the study used cross-sectional data from firms in several different industries. Although we tested for potential industry bias and found no significant differences, it still is possible that industry composition may have influenced the results. Fourth, the research used a multi-informant strategy to collect dyadic data. Although two informants per firm is preferred over single informants, the optimal number of informants to reduce common method bias is three because that would allow comparison of the degree of agreement between responses (Van Bruggen et al., 2002). As collecting triadic data was not possible, we used the weighted means based on informants' experience with portfolio decision-making to create aggregated measures for the portfolio variables. 


\section{References}

Anderson, J. C., and D. W. Gerbing. 1988. Structural equation modelling in practice: A review and recommended two-step approach. Psychological Bulletin 103: 411-23.

Barczak, G., A. Griffin, and K. B. Kahn. 2009. Perspective: Trends and drivers of success in NPD practices: Results of the 2003 PDMA best practices study. Journal of Product Innovation Management 26: 3-23.

Baum, J. R., and S. Wally. 2003. Strategic decision speed and firm performance. Strategic Management Journal 24: 1107-29.

Bordley, R. 2003. Determining the appropriate breadth and depth of a firm's product portfolio. Journal of Marketing Research 60: 39-53.

Braunscheidel, M. J., and N. C. Suresh. 2009. The organizational antecedents of a firm's supply chain agility for risk mitigation and response. Journal of Operations Management 27: 119-40.

Chao, R. O., and S. Kavadias. 2008. A theoretical framework for managing the new product development portfolio: When and how to use strategic buckets. Management Science 54: 907-21.

Chesbrough, H. W. 2002. Making sense of corporate venture capital. Harvard Business Review 80: 90-99.

Cooper, R. G. 2008. Perspective: The Stage-Gate idea-to-launch process: Update, what's new, and NexGen systems. Journal of Product Innovation Management 25: 213-32.

Cooper, R. G., S. J. Edgett, and E. J. Kleinschmidt. 1999. New product portfolio management: Practices and performance. Journal of Product Innovation Management 16: 333-51.

Cooper, R. G., S. J. Edgett, and E. J. Kleinschmidt. 2000. New problems, new solutions: Making portfolio management more effective. Research-Technology Management 43: 18-33.

Cooper, R. G., S. Edgett, and E. Kleinschmidt. 2001. Portfolio management for new products. Cambridge, MA: Perseus Publishing.

Cooper, R. G., S. J. Edgett, and E. J. Kleinschmidt. 2004. Benchmarking best NPD practices-II. Research-Technology Management 47: 50-59.

Eggers, J. P. 2006. Customizing dynamic capabilities: Learning, adapting and focusing in product portfolio management. Paper presented at the annual meeting of the Academy of Management, Atlanta, GA.

Eid, M., F. W. Nussbeck, C. Geiser, D. A. Cole, M. Gollwitzer, and T. Lischetzke. 2008. Structural equation modeling of multitrait-multimethod data: Different models for different types of methods. Psychological Methods 13: 230-53.

Eisenhardt, K. M., and J. A. Martin. 2000. Dynamic capabilities what are they? Strategic Management Journal 21: 1105-21.

Fornell, C., and D. F. Larcker. 1981. Evaluating structural equation models with unobservable variables and measurement error. Journal of Marketing Research 18: 39-50.

Gerbing, D. W., and J. C. Anderson. 1988. An updated paradigm for scale development incorporating uni-dimensionality and its assessment. Journal of Marketing Research 25: 186-92.

Grewal, R., A. Chakravarty, M. Ding, and J. Liechty. 2008. Counting chickens before the eggs hatch: Associating new product development portfolios with shareholder expectations in the pharmaceutical sector. International Journal of Research in Marketing 25: 261-72.

Griffin, A. 2002. Product development cycle time for business-to-business products. Industrial Marketing Management 31: 291-304.

Hair, J. F., W. C. Black, B. J. Babin, R. E. Anderson, and R. L. Tatham. 2005. Multivariate data analysis (6th ed.). Upper Saddle River, NJ: Prentice Hall.

Hauser, J., G. J. Tellis, and A. Griffin. 2006. Research on innovation: A review and agenda for marketing science. Marketing Science 25: 687- 717.

Jansen, J. J. P., F. A. J. Van Den Bosch, and H. W. Volberda. 2006. Exploratory innovation, exploitative innovation, and performance: Effects of organizational antecedents and environmental moderators. Management Science 52: 1661-74.

Kester, L., E. J. Hultink, and K. Lauche. 2009. Portfolio decision-making genres: A case study. Journal of Engineering and Technology Management 26: 327-41. 
Kester, L., A. Griffin, E. J. Hultink, and K. Lauche. 2011. Exploring portfolio decision-making processes. Journal of Product Innovation Management 28: 641-61.

Langerak, F., A. Griffin, and E. J. Hultink. 2010. Balancing development costs and sales to optimize the development time of product line additions. Journal of Product Innovation Management 27: 336-48.

Leonard-Barton, D. 1992. Core capabilities and core rigidities: A paradox in managing new product development. Strategic Management Journal 13: 111-25.

Lin, S. J., and J. R. Lee. 2011. Configuring a corporate venturing portfolio to create growth value: Within-portfolio diversity and strategic linkage. Journal of Business Venturing 26: 489-503.

Lindell, M. K., and D. J. Whitney. 2001. Accounting for common method variance in cross-sectional research designs. The Journal of Applied Psychology 86: 114-21.

McNally, G. C., S. S. Durmusoglu, R. J. Calantone, and N. Harmancioglu. 2009. Exploring new product portfolio decisions: The role of managers' dispositional traits. Journal of Product Innovation Management 38: 127-43.

Narver, J. C., and S. F. Slater. 1990. The effect of a market orientation on business profitability. Journal of Marketing 54: 2035 .

Nunally, J. C. 1978. Psychometric theory (2nd ed.). New York: McGraw-Hill.

Podsakoff, P. M., S. B. MacKenzie, and N. P. Podsakoff. 2003. Common method bias in behavioral research: A critical review of the literature and recommended remedies. The Journal of Applied Psychology 88: 879-903.

Prahalad, C. K., and G. Hamel. 1990. The core competence of the corporation. Harvard Business Review 66: 79-91.

Preacher, K. J., and A. F. Hayes. 2008. Asymptotic and resampling strategies for assessing and comparing inidirect effect in multiple mediator models. Behavioral Research Methods 40: 879-91.

Repenning, N. P. 2001. Understanding firefighting in new product development. Journal of Product Innovation Management 18: $285-300$.

Rothaermel, F. T., M. A. Hitt, and A. J. Lloyd. 2006. Balancing vertical integration and strategic outsourcing: Effects on product portfolio, product success, and firm performance. Strategic Management Journal 27: 1033-56.

Talaulicar, T., J. Grundei, and A. Van Werder. 2005. Strategic decision making in start-ups: The effect of top management team organization and processes on speed and comprehensiveness. Journal of Business Venturing 20: 519-41.

Texas Instruments. 2009. Annual report. Dallas, TX: Texas Instruments. Texas Instruments. 2010. Annual report. Dallas, TX: Texas Instruments. Texas Instruments. 2011. Annual report. Dallas, TX: Texas Instruments.

Van Bruggen, G. H., G. L. Lilien, and M. Kacker. 2002. Informants in organizational marketing research: Why use multiple informants and how to aggregate responses. Journal of Marketing Research 39: 469- 78.

Vorhies, D. W., and N. A. Morgan. 2005. Benchmarking marketing capabilities for sustainable competitive advantage. Journal of Marketing 69: 80-94.

Voss, G. B., M. Montoya-Weiss, and Z. G. Voss. 2006. Aligning innovation with market characteristics in the nonprofit professional theater industry. Journal of Marketing Research 43: 296-302.

Williams, L. J., N. Hartman, and F. Cavazotte. 2010. Method variance and marker variables: A review and comprehensive CFA marker technique. Organizational Research Methods 13: 477-515. 


\begin{tabular}{|c|c|c|c|}
\hline Measures and Sources & Description & $\begin{array}{l}\text { St. Factor } \\
\text { Loadings }\end{array}$ & t-value \\
\hline \multicolumn{4}{|c|}{ MARKET PERFORMANCE } \\
\hline Customer satisfaction & As compared with our competitors over the past three years we have: & & \\
\hline \multirow[t]{4}{*}{$\mathrm{CR}=.88 \mathrm{AVE}=.66$} & Achieved high levels of customer satisfaction & .76 & 16.28 \\
\hline & Delivered value to our customers & .85 & 18.97 \\
\hline & Delivered what our customers want & .75 & 15.94 \\
\hline & Retained valued customers & .61 & 12.16 \\
\hline Market effectiveness & As compared with our competitors over the past three years we have: & & \\
\hline \multirow[t]{4}{*}{$\mathrm{CR}=.88 \mathrm{AVE}=.65$} & Achieved market share growth & .75 & 16.27 \\
\hline & Achieved growth in sales revenue & .85 & 19.89 \\
\hline & Acquired new customers & .75 & 11.78 \\
\hline & Increased sales to existing customers & .61 & 15.02 \\
\hline Profit & As compared with our competitors over the past three years we have: & & \\
\hline \multirow[t]{4}{*}{$\mathrm{CR}=.94 \mathrm{AVE}=.79$} & Increased business profitability & .89 & 21.62 \\
\hline & Increased return on investment (ROI) & .92 & 22.92 \\
\hline & Increased return on sales (ROS) & .90 & 22.38 \\
\hline & Reached our financial goals & .68 & 14.68 \\
\hline \multicolumn{4}{|c|}{ NPD PORTFOLIO SUCCESS } \\
\hline Strategic alignment & Our NPD portfolio is aligned with our business goals & .74 & 16.16 \\
\hline \multirow[t]{4}{*}{$\mathrm{CR}=.91 \mathrm{AVE}=.68$} & Our NPD portfolio is aligned with our innovation strategy & .79 & 17.74 \\
\hline & The projects in our NPD portfolio collectively contribute to achieving our strategic goals & .81 & 18.38 \\
\hline & Our spending on projects for our NPD portfolio is consistent with our business strategy & .77 & 17.06 \\
\hline & The projects funded for development reflect the priorities of our business strategy & .76 & 16.62 \\
\hline \multirow[t]{6}{*}{$\begin{array}{l}\text { Balance } \\
\mathrm{CR}=.86 \mathrm{AVE}=.51\end{array}$} & $\begin{array}{l}\text { Our NPD portfolio is balanced in terms of incremental (improvements) and radical (really new) } \\
\text { projects }\end{array}$ & .64 & 12.94 \\
\hline & Our NPD portfolio has the right number of projects for our available resources & .62 & 12.32 \\
\hline & The projects in our NPD portfolio are balanced across the various development stages (idea-launch) & .66 & 13.28 \\
\hline & Our NPD resources are in balance with the resources needed to execute the projects in our portfolio & .67 & 13.76 \\
\hline & Our NPD portfolio is balanced to mitigate risk across the different projects & .70 & 14.33 \\
\hline & Our NPD portfolio is balanced in terms of serving both growing and mature markets & .66 & 13.28 \\
\hline \multirow{4}{*}{$\begin{array}{l}\text { Maximal value } \\
\mathrm{CR}=.86 \mathrm{AVE}=.61\end{array}$} & Our NPD portfolio contains several high-impact projects in terms of revenues & .53 & 10.48 \\
\hline & Over the past three years we maximized the return on investment from our NPD portfolio & .58 & 11.59 \\
\hline & $\begin{array}{l}\text { We believe that the current composition of our NPD portfolio will maximize long-term ( }>3 \text { years) } \\
\text { profitability }\end{array}$ & .83 & 18.53 \\
\hline & $\begin{array}{l}\text { We believe that the current composition of our NPD portfolio will maximize market share growth } \\
\text { over the long term ( }>3 \text { years) }\end{array}$ & .84 & 18.61 \\
\hline \multicolumn{4}{|c|}{ PORTFOLIO DECISION-MAKING EFFECTIVENESS } \\
\hline Portfolio mindset & At all times, we have an overview of all the projects in our NPD portfolio & .73 & 15.33 \\
\hline \multirow[t]{4}{*}{$\mathrm{CR}=.86 \mathrm{AVE}=.56$} & We have in-depth knowledge about each project in our NPD portfolio & .74 & 15.60 \\
\hline & We understand how each project relates to other projects in our NPD portfolio & .63 & 12.65 \\
\hline & We know at all times how many projects are in which stage of development & .59 & 11.63 \\
\hline & We can readily anticipate where bottlenecks may occur in our development pipeline & .66 & 13.41 \\
\hline Focus & We focus our innovation resources to achieve our NPD portfolio priorities & .64 & 13.07 \\
\hline \multirow[t]{4}{*}{$\mathrm{CR}=.86 \mathrm{AVE}=.56$} & It is clear which projects in our NPD portfolio have priority & .60 & 11.88 \\
\hline & Nothing distracts us from executing our NPD priorities & .71 & 14.84 \\
\hline & Our resource allocation in the short term reflects our long-term NPD portfolio priorities & .64 & 12.85 \\
\hline & We work in a focused manner and do not easily get distracted from our priorities & .79 & 17.22 \\
\hline Agility & We readily change the composition of our NPD portfolio to respond to new strategic opportunities & .69 & 10.34 \\
\hline $\mathrm{CR}=.82 \mathrm{AVE}=.50$ & We proactively change the composition of our NPD portfolio to anticipate to market changes & .63 & 9.30 \\
\hline (Agility-flexibility & We implement NPD portfolio decisions fast & .73 & 13.86 \\
\hline $\begin{array}{l}\mathrm{CR}=.79 \mathrm{AVE}=.66 \\
\text { Agility-speed }\end{array}$ & $\begin{array}{l}\text { Our NPD portfolio decision-making processes are speedy enough to assure that we can quickly act } \\
\text { upon new opportunities }\end{array}$ & .73 & 14.12 \\
\hline $\mathrm{CR}=.86 \mathrm{AVE}=.68)$ & We rapidly change our NPD portfolio priorities when we detect a new market opportunity & .67 & 12.85 \\
\hline
\end{tabular}

